\title{
Unlocking the potential of Google Earth as a tool in invasion science
}

\author{
Vernon Visser • Barbara Langdon • \\ Aníbal Pauchard · David M. Richardson
}

Received: 22 January 2012/Accepted: 14 September 2013/Published online: 8 December 2013

(C) Springer Science+Business Media Dordrecht 2013

\begin{abstract}
Distribution data are central to many invasion science applications. The shortage of good information on the distribution of alien species and their spatial dynamics is largely attributable to the cost, effort and expertise required to monitor these species over large areas. Virtual globes, particularly Google Earth, are free and user-friendly software which provide high-resolution aerial imagery for the entire globe. We suggest this has enormous potential for invasion science. We provide suggestions and tools
\end{abstract}

Electronic supplementary material The online version of this article (doi:10.1007/s10530-013-0604-y) contains supplementary material, which is available to authorized users.

V. Visser $(\bowtie) \cdot$ D. M. Richardson

Department of Botany and Zoology, Centre for Invasion Biology, Stellenbosch University, Matieland 7602, South Africa

e-mail: vernonvisser@sun.ac.za

B. Langdon - A. Pauchard

Facultad de Ciencias Forestales, Universidad de

Concepción, Concepción, Chile

B. Langdon - A. Pauchard

Institute of Ecology and Biodiversity (IEB), Casilla, Chile

B. Langdon

Bioforest S.A., Camino a Coronel km 15 s/n, Coronel, Chile for gathering data on the distribution and abundance of invasive alien trees using visual interpretation of Google Earth imagery, and propose how these data may be used for a number of purposes, including calculating useful metrics of invasions, prioritising species or areas for management and predicting potential distributions of species. We also suggest various practical uses of Google Earth, such as providing a tool for early detection of emerging invasions, monitoring invasions over time, and to help researchers and managers identify suitable field study sites. Virtual globes such as Google Earth are not without limitations and we provide guidance on how some of these can be overcome, or when imagery from Google Earth may not be fit for invasion science purposes. Because of Google Earth's huge popularity and ease of use, we also highlight possibilities for awareness-raising and information sharing that it provides. Finally, we provide the foundations and guidelines for a virtual global network of sentinel sites for early detection, monitoring and data gathering of invasive alien trees, which we propose should be developed as part of a "citizen science" effort. There has been limited use of virtual globes by invasion scientists and managers; it is our hope that this paper will stimulate their greater use, both within the field of invasion science and within ecology generally.

Keywords Early detection - Biological invasions · Google Earth · Monitoring · Remote sensing $\cdot$ Tree invasions $\cdot$ Sentinel sites 


\section{Introduction}

An ever increasing number of species are being moved, both intentionally and unintentionally, by humans from their natural ranges to distant locations (Levine and D'Antonio 2003). Species that successfully establish in these new locations can be problematic because they can alter the structure and functioning of ecosystems (van Wilgen et al. 2008). Some invasive species lead to a loss of biodiversity and ecosystem services (Perrings et al. 2005), and ultimately to substantial economic costs (Pimentel et al. 2000; Le Maitre et al. 2002). Trees represent a special case of invasive alien species for a number of reasons: alien trees were often intentionally introduced for horticultural or forestry purposes (Richardson and Rejmánek 2011); there are often major conflicts of interest in the growing of alien trees e.g. many commercially important species are also invasive species (Richardson and Rejmánek 2011; van Wilgen and Richardson 2012); and alien tree invasions are among the most costly invaders to manage because trees generally produce high biomass and they impact on ecosystem services such as water provision where they invade grasslands and shrublands (Richardson 1998; van Wilgen et al. 2001; Le Maitre et al. 2002; van Wilgen and Richardson 2012).

There is therefore considerable interest in being able to assess the distribution of invasive alien trees (IATs). Distribution data are crucial for many aspects of invasion science including the prioritisation of areas and species for management (e.g. Roura-Pascual et al. 2010), identifying areas that are most vulnerable to invasion (Thuiller et al. 2005), calculating rates of spread and detailing distribution patterns to understand invasion dynamics and plan effective interventions (Higgins et al. 2001; Osunkoya et al. 2012), and identifying environmental and anthropogenic factors associated with invasions (Castro-Díez et al. 2011; Gallagher et al. 2011). Because of their size, trees are generally easier to map than most other groups of invasive species, especially when they invade (as they often do; Rundel et al. 2014) previously treeless vegetation. Despite this advantage, accurate distribution data for invasive trees are difficult to acquire because, to date, they have either been sourced from field observations (e.g. Chytrý et al. 2009) or from aerial products such as photographs or remote-sensing products (Huang and Asner 2009). Unfortunately, there is no systematic, low-cost protocol for measuring the distribution and spatial arrangement of tree invasions at different scales that managers and scientists can use (Wilson et al. 2014). Field observations are time-consuming and expensive and are therefore usually only practical over small geographical areas (Mumby et al. 1999; Kotzé et al. 2010). Aerial photographs and remote-sensing products (obtained directly from the satellite data providers) have the benefits of being able to cover much larger areas, being more easily repeatable, and much cheaper than field observations. However, if aerial photographs are obtained from flight surveys for specific research projects or obtained from government or commercial institutions that fly aerial surveys, or if remote-sensing products are obtained directly from the satellite data providers, they are often expensive to purchase, require a high level of expertise to format and analyse, and sometimes require software and hardware that are beyond the budgets of managers and scientists, especially in developing countries (Underwood et al. 2007). Invasion scientists, managers and organisations with limited resources and technical expertise, therefore, would benefit from a simple and cheap method to conduct assessments of IAT distributions and aspects of their spatial ecology. Knowledge of IAT distributions and abundance can be useful for measuring ecosystem impacts, determining areas with a high risk of invasion, planning IAT management, monitoring invasions over time, early detection of new alien tree invasions and for raising public awareness of IAT impacts.

Virtual globes provide free aerial imagery (aerial photography and/or satellite imagery), which is formatted and stitched together to build a 3D model of the world that users can navigate in "virtual reality" (Butler 2006; Yu and Gong 2012). Virtual globes have several advantages over most traditional 2D GIS software, including the fact that they are generally free, their ease of use, their limited need for local data storage, better visualisation of geographic data (particularly of large datasets), and their capacity to communicate and share information with the public and the scientific community (Stensgaard et al. 2009; Goodchild et al. 2012; Yu and Gong 2012). Most virtual globes share a number of other features, including the capacity for users to add and share their own data, tools for distance and area measurement, visualising topography, etc. (Yu and Gong 2012). 
A number of virtual globes currently exist, including Google Earth (http://www.google.com/earth/index. html), NASA World Wind (http://worldwind.arc. nasa.gov), ArcGIS Explorer (http://www.esri.com/ software/arcgis/explorer/index.html) and many others (see references in $\mathrm{Yu}$ and Gong 2012). Google Earth (GE), launched in June 2005, is by far the most widely-used virtual globe (Yu and Gong 2012) and, consequently, will be the focus of this paper. However, it should be noted that many of the features of GE highlighted in this paper will equally apply to other virtual globes. The popularity of GE is probably due to its ease of use (Stensgaard et al. 2009; Goodchild et al. 2012; Yu and Gong 2012), stability (Aurambout and Pettit 2008), and the ability to import, overlay and visualise geographic data by converting to Keyhole Markup Language (KML) file format (Stensgaard et al. 2009; Goodchild et al. 2012; Yu and Gong 2012). KML has become the standard format for virtual globes, with conversion to this format possible in software such as ArcGIS (ESRI 2009) and the R statistical package (R Development Core Team 2013). The popularity and utility of GE is possibly also due to the availability of high-resolution imagery $(0.5 \mathrm{~m}$ GeoEye and 4 m IKONOS; http://www.geoeye.com; although many regions of the world only have imagery with a resolution of $15 \mathrm{~m}$; Landsat; http://landsat.usgs. gov; Potere 2008), and because there are often images for multiple dates available for any given location (GE provides images from a number of data providers, and many of these are continuously-updated satellite images; Table S1). GE has been widely used by ecologists, geographers, social scientists, palaeontologists and geologists for a wide range of tasks (e.g. mapping bird nests (Hughes et al. 2011), assessing the magnetic alignment of cattle and deer (Begall et al. 2008), verifying a global map of rain-fed croplands (Biradar et al. 2009), measuring the quality of public parks (Taylor et al. 2011), mapping landslides after earthquakes (Sato and Harp 2009) and for disaster management and response (e.g. http://giscorps.org)), but its potential as part of a toolbox for studying the full suite of spatial dimensions of phenomena such as biological invasions has yet to realized.

The aim of this paper is to illustrate the utility of GE as a tool in invasion science, particularly for understanding the dynamics of tree invasions. We highlight a number of the possible uses of GE as a tool for studying tree invasions and illustrate these uses by way of three case studies. We also address some of the limitations of GE for mapping and monitoring tree invasions, and suggest how they might be overcome. We expect that by promoting this low-cost, simple approach to tree-invasion mapping, managers and scientist across the globe will be able to start collecting data of invasion processes that would otherwise have not been spatially and quantitatively assessed.

\section{A brief note on Google Earth imagery}

Google Earth, as commercial software, is "targeted for a mass market audience, and the key drivers are market share and advertising revenue, rather than to advance research" (Yu and Gong 2012). Probably as a result, very little documentation is provided for almost all aspects of imagery acquisition and manipulation (e.g. who provides images and for where, how often images are updated, how images are manipulated, etc.), often making it more difficult for scientists to use GE as a scientific tool. Below we discuss a number of important features of GE imagery that we feel a scientific user should be aware of. Firstly, georeferencing or orthorectification of images in GE is currently not entirely accurate, which causes positional accuracy errors (Potere 2008; Benker et al. 2011; Yu and Gong 2012). Coordinates obtained from imagery in GE have been found to be as far as $171.6 \mathrm{~m}$ away from their actual location (in the horizontal plane), although horizontal positional accuracies were found to be much better in developed countries (24.1 m root-mean-squared error) than in developing countries (44.4 m root-mean-squared error; Potere 2008), and have been found to be as accurate as $2.64 \mathrm{~m}$ root-mean-squared error in the Big Bend region of Texas, USA (Benker et al. 2011). Secondly, the spatial resolution of images is not only dependent on the spatial resolution of the original image, but also on the zoom level i.e. the altitude from which one views an image. Currently GE limits the maximum number of pixels a user can download to 1000 pixels (Google Earth User Guide 2013). This means that only when a user is zoomed into a relatively small area will they be able to save an image at the resolution of the original image. Thirdly, GE images only have three spectral bands (red, green and blue), even if the original imagery had more bands (e.g. GeoEye, which also has a near-infrared band), and these bands have also been 
manipulated to improve the appearance of the image, but the manner in which this is done is unknown and unpublished (Google Earth Blog 2009). Fourthly, very little metadata, other than the name of the image provider and the date the image was taken, are available for GE images. Metadata for SPOT and DigitalGlobe images can be found using the information from the layers provided in the "Layers panel" under the section labelled "More". SPOT metadata are provided in a balloon for each image, and for DigitalGlobe imagery taken between 2002 and 2010 one can obtain the "Catalog ID" for an image and consult the DigitalGlobe ImageFinder (https://browse. digitalglobe.com/imagefinder/main.jsp?) to obtain all the metadata. Alternatively, for DigitalGlobe images taken before 2002 or after 2010, one can use the DigitalGlobe Google Earth Search Service (http:// geofuse.geoeye.com/landing/google-earth/) to find images and their associated metadata. Finally, the availability of GE imagery for different dates, and the spatial resolution of these images, varies considerably around the world. For the 11 sites from Supplementary files 1 and 3 with alien tree invasions that are visible in GE, we found that all sites had a minimum of three images of different dates, and image spatial resolution generally improved over time, with most sites having $1.65 \mathrm{~m}$ spatial resolution GeoEye-1 imagery (Table S1). However, sites in the developed world (USA and Australia) generally had more images than sites in the developing world, and spatial resolution of images was often as good for the oldest images as the newest images, because these were aerial photographs (Table S1). These issues have important implications for the possible uses of GE for studying and monitoring tree invasions, as we discuss in the sections below.

\section{Possible uses of GE imagery for the study of tree invasions}

Mapping tree invasions

Several efforts have been made to delineate the presence of IATs using moderate (10-100 m) and high $(<10 \mathrm{~m})$ spatial resolution imagery (see Huang and Asner 2009 for a recent review), some of which are also available in a formatted form in GE (see Table S1 for a census of imagery sources and spatial resolution at notable tree invasion sites around the world). This suggests that it might be possible to delineate the presence of IATs using GE imagery, as we discuss below in relation to the resolution of the imagery available.

Two approaches for delineating IAT presence using high spatial resolution imagery are possible: using classification algorithms or visual interpretation. Classification algorithms rely on spectral and pattern information to group pixels into different categories, one or some of which will hopefully correspond to the alien species one is trying to detect (Lass et al. 2005), However, even the original, unformatted imagery often only provides limited success for automatic detection of IATs (Huang and Asner 2009), or is only successful when the species of interest occurs in large stands, has unique phenological patterns, and has high spatial and spectral resolution (Huang and Asner 2009). For these reasons, and because the imagery currently available in GE has been manipulated (as described earlier, imagery has low spectral resolution, and due to GE's limitations on the number of pixels one can save in an image, it is difficult to acquire high spatial resolution imagery for large areas), GE imagery is of limited value for delineating the presence of IATs using classification algorithms.

Visual interpretation relates visual characteristics of images, such as colour, texture, shape, size, shadow, pattern, site, height and association, to real-world objects on the ground (Joseph 2005). Although visual interpretation is time-consuming, and interpretation can vary between individuals, humans are able to integrate all the above-mentioned visual characteristics and make deductions in ways that are currently impossible for any algorithm (Joseph 2005). Visual interpretation to delineate the presence of IATs can be aided by plant phenology (e.g. bright flowers at a time of year when other species are not flowering), unique spatial patterns of how an IAT occupies the landscape, and large monospecific stands of an IAT (Huang and Asner 2009). Visual interpretation of GE imagery can be enhanced by a number of tools. For example, the polygon tool allows users to manually delineate canopy boundaries and save these in Keyhole Markup Language (KML) format, the native format of GE. Alternatively, the placemark tool allows users to pinpoint the coordinates of individual trees, also with the ability to save these in KML format. The capability of viewing imagery from different dates also aids in IAT canopy delineation. Trees are generally 
long-lived and the same individuals will consequently often be visible in images acquired on a different date. Therefore, a tree that is indistinct in one image (e.g. due to shadows or poor image resolution), may be more visible in an image acquired on a different day.

While moderate spatial resolution imagery (e.g. Landsat, SPOT and ASTER) is of too low resolution to delineate individual trees, it can be used to map IAT canopy cover in certain circumstances. Canopy cover is defined as "the proportion of the forest floor covered by the vertical projection of the tree crowns" i.e. for an individual tree, canopy cover is the area on the ground that is encompassed by the boundaries that are vertically below the outer edge of the tree canopy (Jennings et al. 1999). Moderate spatial resolution imagery (including free Landsat imagery) has been successfully used to map landscape-scale changes in tree (not necessarily alien) canopy using a variety of indices calculated using information from different spectral bands (e.g. Breshears et al. 2005; Bradley and Fleishman 2008; Huang et al. 2009; Becker et al. 2013), suggesting that similar approaches could work with the same or similar-resolution imagery from GE. However, the low spectral resolution of GE imagery, and the lack of information on how the spectral information has been manipulated, probably limits opportunities for using such approaches. Visual interpretation, therefore, seems to be the more appropriate approach for estimating IAT canopy cover with moderate spatial resolution imagery from GE. Using visual interpretation of GE imagery, canopy cover can either be estimated by the area of the polygon used to delineate the canopy boundary, or if canopy boundaries are indistinct, a grid with a resolution smaller than the average canopy size can be projected onto a GE image and canopy cover can be estimated by the number of grid cells the canopy is seen to occupy. Stand canopy cover would logically be the sum of individual tree canopy covers within a predefined area.

We have suggested how one might use visual interpretation to delineate individual IATs or IAT canopies from moderate and high spatial resolution GE imagery. However, visual interpretation is not always an easy task, especially when trees are visually similar to the natural, dominant vegetation (e.g. alien trees in a temperate, broadleaf forest (Boschetti et al. 2007), or Acacia trees in a low shrubland (Stow et al. 2000). Furthermore, image resolution and quality is highly variable in GE making detection of individual trees or stands of alien trees difficult when these cooccur with other vegetation types. As a rule of thumb, users might reliably only attempt visual interpretation when imagery is provided by DigitalGlobe or one of the other high-resolution imagery providers to GE (see Table S1). GE is continuously updating its image coverage, slowly reducing low-resolution gaps. Other issues, such as cloud cover and plant phenology (seasonality of image capture), may also limit tree recognition and mapping, and may be more problematic in certain regions. Field verification of IAT presence will be necessary when using visual interpretation of GE imagery, at least for a subset of the area(s) studied, and will logically be required for all of the other applications of GE that we suggest below (other than \#5, "Sharing information online with other users and promoting global networking"), as they are all dependent on IAT distribution information.

Delineating the distribution of individual IATs and mapping IAT canopy cover can have a number of important applications. Canopy cover is a good estimate of species abundance and biomass and, therefore, it can also be used as a crude metric for indicating the magnitude of ecosystem impacts for species recognized as ecosystem engineers such as Acacia species and pines (Richardson and Rejmánek 2011). Such data are increasingly required to prioritize areas for management intervention (Roura-Pascual et al. 2009). Spatial information about IATs can have other useful applications for science and management. Locations of individual IATs can be used to extract data for hypothesised drivers of IAT presence from spatially-referenced layers within a GIS environment. These can be used to test whether the presence of an invasive species is associated with any environmental or anthropogenic factors (e.g. Alston and Richardson 2006). Alternatively, these can be used to make predictions of habitat suitability for an IAT species, including niche modelling, which can be used for locating areas with a high risk of invasion or prioritising management of IATs (Richardson and Thuiller 2007). It should, however, be noted that due to the positional errors of GE imagery described earlier, the exact locations of polygons and placemarks representing IATs may not be entirely accurate. This is not necessarily problematic for the applications mentioned above, as IAT canopy cover is a relative measure, and the other applications (e.g. niche modelling) generally rely on coarse resolution 
environmental datasets, which have resolutions far greater than the positional inaccuracies of GE imagery (e.g. kilometres for the former, but hundreds of metres for the latter). However, if the intended use of the IAT location data generated using visual interpretation of GE imagery requires high spatial accuracy, one could attempt to manually georeference the GE image in GIS software beforehand. One can use objects with known locations (e.g. roads) to georeference an image, but this will require having enough locations with precise coordinates (which may not always be possible), and having such points evenly distributed across the area of interest. We illustrate how this might be done in our second case study.

Measuring specific metrics of invasions

A number of useful metrics rely on knowing either the distribution or abundance of an alien species (Wilson et al. 2014). The distance an alien species has spread from a source population can be useful for determining whether the invasion process has progressed to a stage at which recruitment is occurring outside of the parent population, at which time the invasion process is increasingly driven by propagule pressure of invading metapopulations (Rouget and Richardson 2003) and becomes much more difficult to manage (Higgins et al. 2000; Langdon et al. 2010). The relative abundance of an alien species has been proposed as a useful metric for identifying dominant alien species, environments that are heavily invaded and/or susceptible to invasion, and for predicting the progress of an invasion (Catford et al. 2012). In addition to abundance, the spatial pattern of invasive plant populations has been shown to influence invasion progress (Higgins et al. 2001); metrics such as the degree of aggregation, which can be calculated from mapping individual trees, have much potential in this regard.

By visually interpreting the imagery available in GE (when this is of high enough spatial resolution), and thereby identifying individual IATs and/or calculating canopy cover of these species, all of the metrics we described above can be estimated. Spread distances can be estimated using GE imagery by identifying the source population of an IAT species (e.g. a plantation) and measuring the distance between the source population and individuals that have spread into neighbouring vegetation (identified using visual interpretation). This can either be done manually, using the distance tool in GE, or by exporting the polygons or placemarks representing identified IAT individuals, and using tools available in a GIS environment. The relative abundance of an alien species and spatial pattern metrics such as the degree of aggregation will require the exporting of polygons representing identified individual IATs to software such as (R Development Core Team 2013). We illustrate how this might be achieved in our case studies. All of the abovementioned metrics are, however, dependent on the positional accuracy of GE imagery, as described earlier, and manual georeferencing of the imagery may be necessary.

\section{Monitoring tree invasions}

With the availability of imagery for different dates, and the promise of future imagery in GE (from satellites such as GeoEye-1), tree invasions can be spatially monitored over time. The rate of change in IAT canopy cover can be used for prioritising management efforts (Maxwell et al. 2009) and for understanding the factors contributing to invasiveness (Rouget and Richardson 2003), and is easily estimated if suitable imagery is available for more than one date in GE. Spread distances measured for more than one date can be used to calculate rates of spread, and this can be related to various characteristics of the invasive species, such as its residence time and morphological traits, to develop predictions of problematic species in the future (Ahern et al. 2010). It may also be possible, in some instances, to identify combinations of environmental factors that trigger particular invasion events by observing when an IAT species first spreads beyond the boundaries of its source population (Becker et al. 2013; Robinson et al. 2008). Multiple observations, like this, for a given species at different localities is useful for identifying key drivers of invasion (Richardson et al. 2004).

When viewing images obtained on different dates it is sometimes apparent that there is a shift in the location of fixed objects (e.g. buildings, roads, mountains), which is related to the inaccuracies in georeferencing or orthorectification of images in GE, resulting in positional inaccuracies, as described earlier. We suggest that these spatial errors can be accounted for, to some extent, by manually georeferencing images obtained on different dates in GIS software using objects identifiable in all images and 
known to have fixed locations (e.g. roads, large boulders or trees), although this does increase the amount of time required to do these types of analyses considerably.

Early detection and locating field sites

Early detection of newly-emerging invasions is often more cost effective and ensures a much greater chance of eliminating an invader than waiting for an alien species to become highly abundant (Rejmánek and Pitcairn 2002; Hulme 2006; Mehta et al. 2007). Remote sensing has long been proposed and used as an early detection tool (Hulme 2006). However, remote sensing may have limited utility if a species is "cryptic, small, scattered or highly mobile" (Hulme 2006). Invading trees are less likely to be difficult to detect in this regard than other plant life-forms because of their large size. Most tree species are relatively slow-growing and slow to mature and so should become visible in aerial imagery before they start producing many propagules. Undoubtedly, fieldtruthing should complement GE observations, especially when new invasions are being reported. There is always a risk of false positives, especially in areas where native species have similar visual characteristics to the IAT species.

GE imagery may also be useful to invasion scientists for identifying potential field sites. Researchers may want, for example, to conduct a study using sites where the full spectrum of IAT relative abundance is represented. GE provides the opportunity to remotely and cheaply characterise a number of potential study sites in terms of the metric the researcher is interested in (relative abundance in this example), and select only the ones that match the desired criteria. IAT managers may wish to identify field sites for the purposes of management prioritisation e.g. selecting either sites that are the most or least invaded for urgent clearing operations. All of this can be done using GE imagery in a much more cost- and time-effective manner than by either conducting field assessments or purchasing aerial imagery. Scientists can also share the locations of their study sites in a much more accurate and straightforward manner by uploading their field sites onto GE e.g. as placemarks or in KML format. In the long-term it would be most useful to have a central online repository for these types of data, although this is currently beyond the scope of the aims of this manuscript.

Sharing information online with other users and promoting global networking

GE has been widely used to disseminate information in a visually-appealing, informative and educational manner. For example, Conroy et al. (2008) illustrate how GE can be used for sharing paleontological spatial information with people who have no background or familiarity with GIS. Spatial data layers can be exported in KML format and easily opened by anyone with GE on their computer, negating the need for complicated GIS software (Conroy et al. 2008). While there are nice examples of invasive species distributions mapped onto GE imagery (e.g. http:// calweedmapper.calflora.org/), the use of GE itself for sharing invasive species spatial data, to the best of our knowledge, has only had limited applications to date. We suggest that GE could be used much more widely used for invasion science applications.

First and foremost it could be used for educational or awareness-raising purposes to highlight the often dramatic changes effected by tree invasions. There are numerous examples around the world where the spread of IATs is quite clearly visible in the aerial imagery provided by GE. We have created a KML file with some notable invasion sites to highlight the utility of GE in this regard (Supplementary file 1).

Secondly, GE provides an excellent platform for invasion scientists and managers to network and share their results and data in the form of KML files. We know of only a very few papers providing supporting information in this format, but that number should increase, given that this is such an easy and effective way of visualising data and results. Global networks of researchers and managers can benefit from the direct transfer of data and results (see Pauchard et al. 2009, Sagarin and Pauchard 2010), especially with the use of an interactive platform such as GE. For example, scientists studying tree invasions into treeless ecosystems can compare a number of environmental attributes across global sites if they have accurate positions for such invasions, while managers can learn from other regions where management actions have already been conducted (see e.g. Kueffer et al. 2013). To highlight the effectiveness of using the KML format, 
we have provided supplementary KML files for all of our case studies.

Thirdly, monitoring and/or sharing of information on IATs can be achieved using cloud-based GIS servers (e.g. ArcGIS server, GeoServer) that integrate the capabilities of virtual earth applications such as GE with more advanced GIS tools, all accessible online. This sort of approach has been used, for example, for developing an online monitoring system for transmissible diseases (Yang et al. 2012). This approach holds great promise for gathering and sharing information on alien species in general, but requires a high level of technical expertise and an in-depth review of this approach is beyond the scope of this paper.

\section{Sentinel sites}

We have already established the utility of GE in detecting newly-emerging tree invasions and monitoring IAT spread over time. We propose that these capabilities allow for the establishment of a global network of "sentinel sites" for detecting invasions of IATs at an early stage of the invasion process and monitoring the spread of IATs. The idea of having a network of sentinel sites for monitoring or detecting biological changes or phenomena is not new and has been most widely applied to monitoring the spread of infectious diseases (e.g. Freedman et al. 2008; Sserwanga et al. 2011), but has also been used for detecting the spread or arrival of alien species (Meyerson and Mooney 2007) and a national system for detecting emerging plant invasions in the United States was proposed (Westbrooks 2003), but never enacted. The idea behind most sentinel networks is to have a relatively small number of sites spread across a broad, but defined geographical area, at which detailed analyses can be made in order to detect the biological change or phenomenon in question or to indicate changing trends which could trigger management interventions. Such a network, at the global scale, has previously been proposed "to monitor reproduction and regeneration dynamics of alien species", especially alien tree species growing in plantations or arboreta (Richardson and Rejmánek 2004).

The amount of introduction effort, which ultimately contributes to the amount of propagule pressure, has been identified as a principal driver of new invasions (Huang et al. 2012) as have sites of likely entry for an invasive species (Hulme 2006). Plantations of alien trees have been a major source of IAT invasions (Richardson and Rejmánek 2011; Dodet and Collet 2012), and should form part of any proposed sentinel site network. Other areas that are likely to act as sources of propagules and sites of entry for new invasions are areas of human habitation where gardens have been established (Alston and Richardson 2006), and experimental plantings, arboreta or botanical gardens containing alien species (Hulme 2011).

Google Earth provides us with the perfect tool to set up such a global sentinel site network for IATs, because imagery is continuously being updated, it is free and low-tech and, as shown in this paper, is a useful tool for detecting IAT invasion and provides valuable information on the ecology of IATs. In addition, the popularity of GE could enable monitoring of this network of sentinel sites as part of a "citizen science" effort (Silvertown 2009). As described earlier, data sharing via KML files is simple and would allow for easy sharing of locations of sentinel sites. In addition, GE already has the capacity for users to upload photographs (via Panoramio; www. panoramio.com), which would allow for more accurate species identification and verification. The other useful tool in GE which could be used in some instances for verification and identification purposes is Google Street View, which gives on-the-ground imagery for sites close to roads, although this is only available for a limited number of countries, and most extensively in urban areas. Up-to-date monitoring of sites can also be achieved by signing up to receive updates from Google as to when new imagery becomes available in GE for registered locations (https://followyourworld.appspot.com/dashboard).

Such a global network would obviously be limited by the biases in the availability of high resolution imagery in GE, but as previously mentioned, continuous updates from satellites such as GeoEye- 1 should lead to ever greater availability of high spatial resolution imagery for all parts of the globe.

We believe that such a sentinel site network will help to: (1) identify emerging trends in IAT invasions; (2) provide valuable locality information for particular IAT species; (3) monitor changes in IAT species abundance and distribution over time; (4) help ensure legislative compliance of land managers and plantation owners; and (5) track management efforts over time. Such a network of sentinel sites might be established by identifying sites close to alien-tree 
propagules within a GIS framework using, for example, land-cover classifications, which include categories for alien tree plantations and urban areas (see case study 3). Alternatively or complimentarily, the network might be grown over time from sites suggested by GE users.

\section{Case studies for illustrating the utility of Google Earth in invasion science}

Case study 1: Pinus contorta invasions in southern Chile

Afforestation using alien tree species has rapidly expanded in the last century (Sedjo 1999), with pine (Pinus) species being among the most commonly planted species (Richardson 1998; Sedjo 1999; Richardson and Rejmánek 2011). A number of pine species have become highly successful invaders in many parts of the globe (Richardson 1998; Richardson and Rejmánek 2011), have a wide range of impacts (e.g. Richardson and van Wilgen 2004), and have been the target of substantial control efforts (e.g. van Wilgen et al. 2012). Pinus contorta is one of the most invasive pine species, being recorded as invasive in Argentina, Chile, Australia, New Zealand and Sweden (Langdon et al. 2010). P. contorta was only introduced relatively recently into Chile as a plantation species $(\sim 1970$ s) and therefore little is known about the spread of this species into native grassland and steppe vegetation (Gundale et al. 2014). Invasions of this species and other conifers have lagged behind such invasions in many other parts of the southern hemisphere because of the shorter history of plantings for forestry (Richardson et al. 2008). Langdon et al. (2010) conducted field surveys next to five different plantations of $P$. contorta in southern Chile in order to determine whether first-generation invaders (i.e. recruits from plantations) were reproducing and thus contributing to the spread of the species, or whether recruitment was still predominantly from plantation trees. We compare the numbers of $P$. contorta individuals recorded at one of the Langdon et al. (2010) study sites, near the city of Coyhaique in southern Chile, with those obtained using GE imagery.

Langdon et al. (2010) originally laid out three $150 \mathrm{~m}$ transects at this study site, but due to the inaccuracies associated with GPS measurements and with the horizontal positional accuracy of GE images (as described earlier), we were unable to ascertain the exact location of these transects in GE. We therefore adopted a different approach, creating 32 "virtual" transects around the presumed location of the original field transects (i.e. $16 \times 3 \mathrm{~m}$ wide transects either side of each straight line joining the GPS measurements representing the three transects laid out by Langdon et al. (2010)). Our virtual transects were created in R (R Development Core Team 2013) using $150 \mathrm{~m}$ long polylines perpendicular to the edge of the $P$. contorta plantation, with the transects further subdivided into subtransects $10 \mathrm{~m}$ long (which is the same distance Langdon et al. (2010) used for their subtransects; Supplementary file 2). Within the area encompassed by these "virtual" transects, we used GE imagery taken on 28 February 2010 (the date closest to January 2009 when the field measurements were obtained; Image supplied by DigitalGlobe, IKONOS-2; $4 \mathrm{~m}$ spatial resolution) for visual interpretation in order to identify $P$. contorta individuals. Trees were generally identifiable against the native grassland matrix by circular patches with a slightly different colour to the surrounding vegetation, and a shadow on the SW side of these patches. Using the polygon tool in GE, we outlined what we identified as the canopy boundary of $P$. contorta trees and saved these in KML format (Supplementary file 2). In Quantum GIS (QGIS; Quantum GIS Development Team 2012) we used the "Join attributes by location" tool to calculate the numbers of polygons (i.e. $P$. contorta individuals) in each subtransect.

The mean number of GE-delineated trees per transect (i.e. the mean of the 32 virtual transects for each $10 \mathrm{~m}$ subtransect) exhibited a positive association with the field-counted number of trees of Langdon et al. (2010) (Fig. 1a, b). However, for higher densities of trees, we under-estimated the actual number of trees in the field (Fig. 1a, b). These high density subtransects appear to be those close to the plantation edge (point size is proportional to distance from plantation edge in Fig. 1a) and those with tall trees (point size is proportional to tree height in Fig. 1b; height of the tallest tree in each subtransect was recorded by Langdon et al. (2010)). This suggests that we were unable to detect smaller trees beneath the canopies of larger trees close to the plantation edge. However, we found a similar decline in tree numbers towards the end of the $150 \mathrm{~m}$ transects using GE imagery as was 


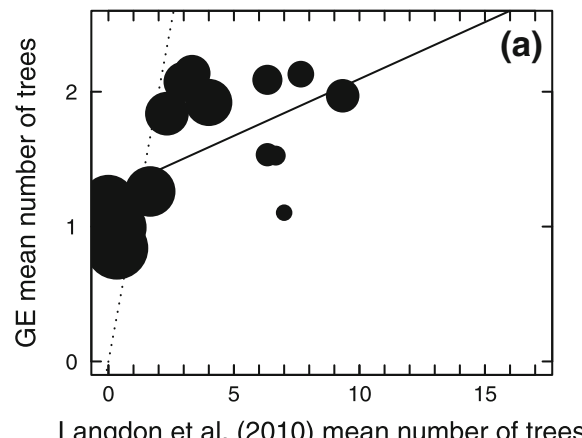

Langdon et al. (2010) mean number of trees

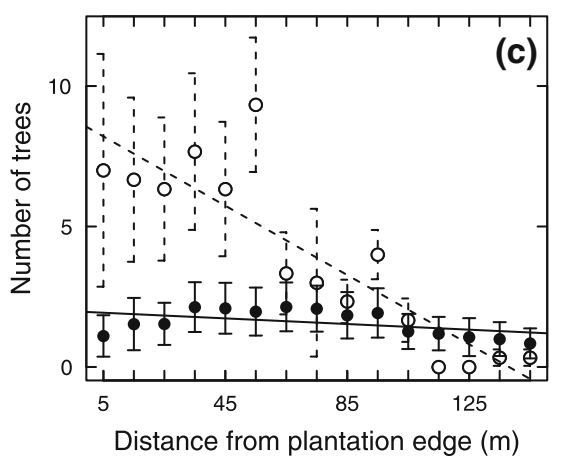

Fig. 1 a, b A comparison of the number of trees counted in the field around Coyhaique city, Chile, by Langdon et al. (2010) and those identified using GE imagery. Point size in $\mathbf{a}$ is proportional to the distance from the plantation edge and in $\mathbf{b}$ to the height of the tallest tree per substransect. The solid line in $\mathbf{a}$ and b represents the linear fit between the field- and GE-counted numbers of trees $\left(\mathrm{y}=0.084 \mathrm{x}+1.251 ; r^{2}=0.31 ; p<0.05\right)$ and the dotted line represents a 1:1 fit between these variables. c Numbers per subtransect of Pinus contorta trees across the $150 \mathrm{~m}$ length of the field transects (open circles are means per subtransect of the three field-based transects; dotted line is the

found with the field transects (Fig. 1c). Inspection of the study area in GE indicates that there are very few $P$. contorta trees further than $150 \mathrm{~m}$ from the plantation edge. These results suggest that using GE imagery for counting individual trees will only work for counting large, mature trees that occur in low to intermediate densities, but will always underestimate the numbers of juveniles, especially when these occur under the canopies of larger trees. It is also worth noting that the spatial resolution of the imagery for the study location was only $4 \mathrm{~m}$ and that higher resolution imagery (e.g. from the GeoEye-1 satellite, with a spatial resolution of $0.5 \mathrm{~m}$; Table $\mathrm{S} 1$ ) would probably enable us to make more accurate counts of tree numbers. In a study of Melaleuca invasion in Florida, also using $4 \mathrm{~m}$ spatial resolution IKONOS imagery,
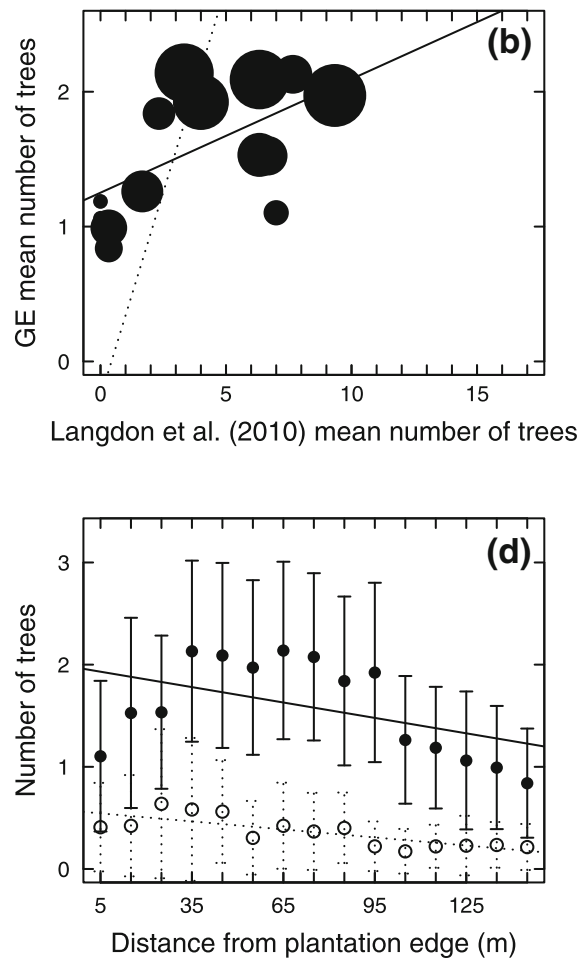

linear fit: $\left.\mathrm{y}=-0.062 \mathrm{x}+8.514 ; r^{\mathrm{r}}=0.78 ; p<0.001\right)$ and of the virtual transects conducted in GE (closed symbols are means per substransect of the 96 virtual transects; solid line is the linear fit: $\mathrm{y}=-0.005 \mathrm{x}+1.956 ; r^{2}=0.23 ; p=0.07$ ). Error bars represent $95 \%$ confidence intervals. d A comparison between 2004 and 2010 of the numbers per subtransect of $P$. contorta trees across the $150 \mathrm{~m}$ length of the field transects. Solid symbols and lines are as for c. Open circles are the 2004 means per substransect and the dotted line is the 2004 linear fit $(\mathrm{y}=$ $\left.-0.002+0.558 ; r^{2}=0.62 ; p<0.001\right)$

but using neural network classification, it was found that this method was unable to identify individuals or stands of Melaleuca when canopy cover dropped below about $50 \%$ of the pixel (Fuller 2005). Other studies using similar high-resolution imagery have had similar results when canopy cover of the IAT under study is less than $50 \%$ of the pixel (Asner and Huang 2011). This case study reiterates our earlier points about "mapping tree invasions" (section "Introduction") in that moderate spatial resolution GE imagery is probably better suited to measuring canopy cover, rather than numbers of individual IATs. Visual interpretation for counting the number of IAT individuals is, therefore, probably better attempted with imagery of very high resolution (e.g. $0.5 \mathrm{~m}$ GeoEye-1 imagery) and only when one is interested in the 


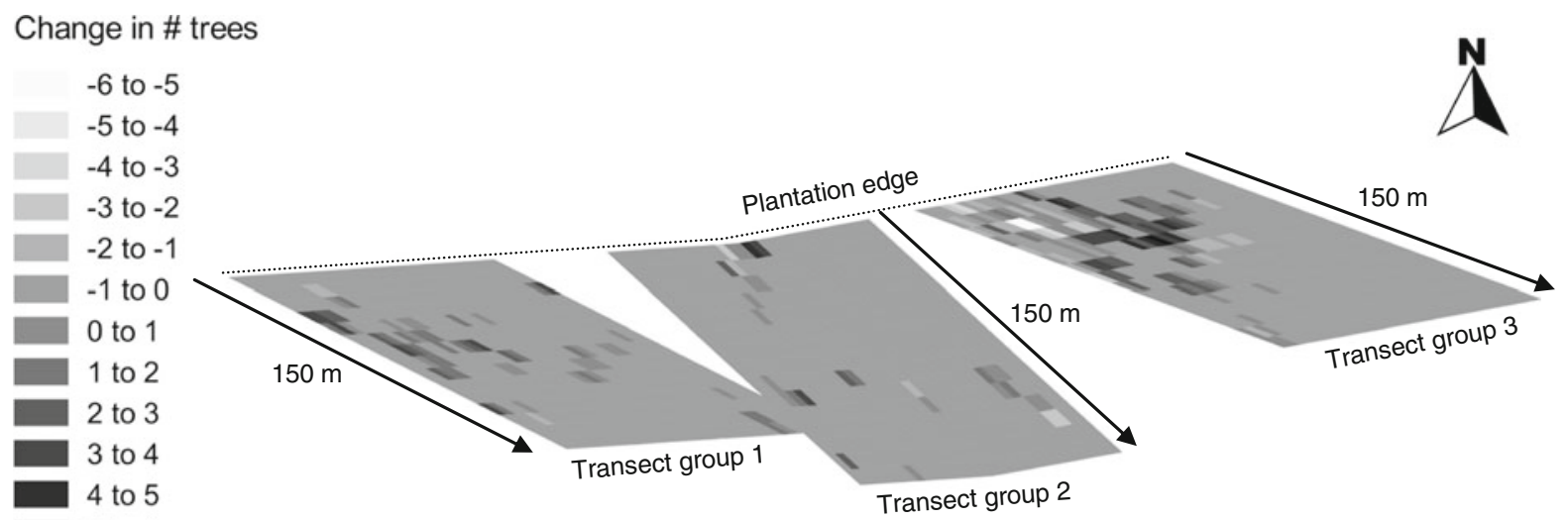

Fig. 2 The change in numbers of Pinus contorta trees around Coyhaique city, Chile, per $10 \times 3 \mathrm{~m}$ subtransect between 2004 and 2010 determined by visual inspection of imagery from GE. For each of the three field transects conducted by Langdon et al. (2010), we created 32 virtual transects measuring $150 \times 3 \mathrm{~m}$ starting at the plantation edge and heading outwards perpendicularly from the edge, resulting in three "transect groups" (see

number of mature trees i.e. not trees with a canopy extent smaller than the image spatial resolution.

To demonstrate the utility of GE in monitoring invasions over time, we performed the same visual inspection of GE imagery and delineation of $P$. contorta trees for an image taken on 25 December 2004 (Image supplied by DigitalGlobe; IKONOS-2; $4 \mathrm{~m}$ spatial resolution). It should be immediately obvious when viewing the study area in GE for this date that objects are displaced further to the NE than in the 2010 image. To correct for this, we georeferenced the 2004 P. contorta polygons to the 2010 image in QGIS (Quantum GIS Development Team 2012) using trees that were identifiable in both images as reference points. A comparison of the numbers of $P$. contorta trees in 2010 with those in 2004 reveals a large overall increase in the mean numbers of these trees in the intervening period (Fig. 1d). We visualised the change in numbers of $P$. contorta trees per subtransect between 2004 and 2010 in GE as a KML file using the free software, shp2kml 2.0 (http://zonums.com/ shp2kml.html; Supplementary file 2), and provide it as a figure in this paper (Fig. 2). This gives us a much clearer perspective of the patchy pattern of increasing abundance of $P$. contorta than Fig. 1d would suggest (Fig. 2; Supplementary file 2). It also supports our hypothesis that we are unable to accurately count trees at high densities, because the largest decreases in $P$. case study 2 for more details). This same figure (in colour) is provided as a KML file in Supplementary file 2. Decreases between 2004 and 2010 in the number of trees identified in a $10 \times 3 \mathrm{~m}$ subtransect are represented by white to light grey; increases by darker grey to black. White areas outside of each group of 32 transects were not included in this analysis

contorta numbers occurred in the third transect in an area of obviously high tree abundance in 2010 (Fig. 2; Supplementary file 2). This visualisation shows how one can easily display results in an attractive format in GE. Overall, this case study highlights the utility of GE for analysing trends in the abundance (numbers of individuals or canopy cover) of IATs over time, although our results suggest that this approach works better for measuring IAT canopy cover, because we tended to underestimate numbers of individual IATs when these were small and/or when these occurred beneath larger trees. However, it also illustrates how much more easily one can remotely characterise an invasion for a much broader area than would be possible in the field, especially for remote regions with difficult access, such as Patagonia. Therefore, such a method could be adopted, as a first approach, by companies and NGOs to remotely assess levels of tree invasions, especially in areas certified under environmental standards such as the FSC (Forest Stewardship Council).

Case study 2: Acacia dealbata invasions in central Chile

Acacia dealbata (Silver wattle) is native to SW Australia and Tasmania and has been widely introduced into other parts of the world for forestry and 
ornamental purposes, and has subsequently become invasive in California, Portugal, New Zealand, Madagascar, South Africa and Chile (Underwood et al. 2007; Richardson and Rejmánek 2011; Richardson et al. 2011). A. dealbata produces abundant yellow flowers mid-winter and this phenological characteristic has been used to successfully identify and measure the canopy cover of this species in forest and riparian habitats in Chile using very high resolution aerial photography (Pauchard and Maheu-Giroux 2007). We investigated whether it is possible to accurately assess the canopy cover of this species using GE imagery, comparing our results with those obtained using aerial photos for a study site along the Rio Nuble near the city of Chillán in central Chile (Lab. de Invasiones Biológicas (LIB), unpublished data).

Using this colour aerial photography (with a 1:20,000 resolution) and visual photointerpretation, the presence or absence of $A$. dealbata trees in flower was determined in $10 \times 10 \mathrm{~m}$ cells of a $2 \times 2 \mathrm{~km}$ grid, with the ultimate finding that this species is highly abundant along riverbanks in the study site. We include a correctly georeferenced KML file of these unpublished results as a supplementary attachment, which, once opened in GE reveals that there is an obvious horizontal displacement of the imagery in GE towards the south (Supplementary file 3). Unless this displacement is corrected, it would be impossible to compare results obtained from GE imagery with those from the aerial photos. The approach we took to address this issue was to save the GE image for 9 March 2010 (the date closest to August 2009 when the aerial photograph was taken; Image provided by DigitalGlobe; IKONOS-2; $4 \mathrm{~m}$ spatial resolution) and georeference this image in QGIS (Quantum GIS Development Team 2012). We used four control points, as close as possible to the corners of the image, and the default thin plate spline transformation and nearest neighbour resampling method in the Georeferencer plugin of QGIS to georeference this image.

Rather than use a grid-based approach for identifying the presence of A. dealbata trees as used with the aerial photos, we used a polygon method similar to that described in the first case study (i.e. Pinus contorta in Chile) to identify stands of this species. Because we were more interested in measuring canopy cover than numbers of individuals of this species, we used polygons to define the boundaries of dense stands of A. dealbata rather than of individual trees.
However, we did not use the polygon tool in GE, but rather conducted this visual interpretation of the GE image in QGIS. The reason for adopting this approach was that we know of no easy method to georeference a vector type file, like the polygons created in GE. The disadvantage of this approach is that the saved GE image will have its resolution fixed at the maximum allowed by GE for saved images and not by the resolution of the original imagery, as is the case if one were viewing the image in GE. Therefore, the saved image will have a coarser resolution if one zooms into a smaller portion of the image and this approach will, consequently, work much better for images with a smaller spatial extent. Alternatively, a combined approach could be used, in which areas with doubtful photointerpretation can be zoomed into using GE, and the interpretation can be conducted using the fixed image. For this reason, we focussed our analysis of GE imagery to a number of islands in the Rio Nuble, representing a very local scale. We also focussed on this specific area because these islands appear to be highly dynamic over time and a cursory inspection of the historical imagery in GE suggested the distribution of $A$. dealbata on these islands has changed considerably over time. To study these temporal changes, we georeferenced a GE image taken on 10 September 2003 (Image provided by DigitalGlobe; IKONOS-2; $4 \mathrm{~m}$ spatial resolution) and performed the same A. dealbata identification procedure using polygons to delimit stands of this species. We then estimated the presence or absence of $A$. dealbata in each of the $10 \times 10 \mathrm{~m}$ grid cells using the QGIS "Join attributes by location" tool.

If we regard the image classification using the highresolution aerial photography as a true estimate of the cover of $A$. dealbata, the classification performed using the 2010 GE imagery shows a high level of accuracy (Accuracy $=84.4 \%$; Table 1) and low omission error (false absences; $4.49 \%$; Table 1). However, there was high commission error (false presences; $53.5 \%$; Table 1) and the Kappa statistic indicated moderate agreement between the GE-based classification and the high-resolution-aerial-photography classification $(\kappa=0.588$; Table 1$)$. The high commission error $(831 / 1553$ grid cells; i.e. a large number of false positives) is as a result of us estimating a far greater number of grid cells to be occupied by A. dealbata based on the 2010 GE image than that estimated using the aerial photographs. We suggest 
Table 1 Accuracy of Acacia dealbata presence/absence classification for a Google Earth image of a study site along the Rio Nuble near the city of Chillán in central Chile compared to presence/absence data obtained using a high-resolution aerial photograph

GE classification High-resolution, aerial photograph classification

\begin{tabular}{lccc}
\cline { 2 - 4 } & Presence & Absence & Row total \\
\hline Presence & 722 & 831 & 1,553 \\
Absence & 34 & 3,956 & 3,990 \\
Column total & 756 & 4,787 & 5,543
\end{tabular}

Accuracy $=84.4 \%$; Omission error $=0.9 \%$; Commission error $=53.4 \%$; Kappa $=0.588$

that this is because our classification perhaps more closely represents the area occupied by all tree species, and not just of $A$. dealbata. It is almost impossible to distinguish between tree species using imagery, such as that available from GE, which has low spectral resolution but, as in this case, high spatial resolution unless the species one is trying to identify has a distinct flowering phenology and/or spatial pattern (Huang and Asner 2009; Asner and Huang 2011). A. dealbata does in fact have a distinct flowering phenology, with abundant yellow flowers in winter, but the GE imagery for 2010 was taken at the wrong time of year (March) to see this. One may notice that the GE imagery available for 10 September 2003 (in the austral spring) shows hints of the yellow flowers characteristic of $A$. dealbata, but is not of high enough spatial resolution to accurately delineate canopies of this species. The identification of $A$. dealbata in the high-resolution aerial photograph relied on the visibility of their yellow flowers, but we argue that younger trees are unlikely to be identifiable in this manner because they are smaller and produce no/fewer flowers, suggesting that the estimated cover of this species obtained using these images is an underestimate. We know from field observations that $A$. dealbata is in fact the most abundant woody plant in this area, although there are also native riparian tree species. GE has clear advantages in terms of costs compared to the high-resolution aerial photography and, therefore, can serve to estimate the cover of Acacia dealbata at local scales, including some field-truthing to adjust for error or bias in the visual estimation. However, our results also highlight the difficulty of mapping canopy cover of IATs invading areas where native trees are also present, and as we suggested in the previous case study, using GE imagery for mapping IAT distributions is likely to be most useful in "treeless" vegetation types such as grasslands, steppe, etc.

Time-series measurements of IAT canopy cover change, however, possibly present a much more successful use for GE imagery. For example, at our study site, a comparison of the 2003 GE image with that of 2010 shows that there have been substantial changes to the sizes and positions of some of the river islands between 2003 and 2010 (Fig. 3a, b). According to our polygon delineations of stands of $A$. dealbata in 2003 and 2010, we found that while the overall area occupied by this species changed very little from $2003\left(0.114 \mathrm{~km}^{2}\right)$ to $2010\left(0.106 \mathrm{~km}^{2}\right)$, there was an increase in abundance of this species on the northern edges of a number of the islands and on some of the previously unoccupied sandbanks of 2003 (Fig. 3a, b). It appears as if this species is able to rapidly colonise areas in the river that have only recently stabilised, such as the sandbanks in the northern branch of this river. We provide a KML file showing the changes in the presence or absence of $A$. dealbata between 2003 and 2010 based on the $10 \times 10 \mathrm{~m}$ grid cells used with the aerial photographs, which we georeferenced back to the 2010 GE image. White indicates stable presence between 2003 and 2010, blue indicates presence in 2003, but not 2010 , and red indicates presence in 2010, but not 2003 (Supplementary file 3). Our results suggest that, together with a priori knowledge of the presence of an IAT species invading native vegetation that includes a considerable native tree component, timeseries analysis of GE images can help to measure how and where change occurs over time.

Case study 3: Designing a sentinel site network for the Western Cape of South Africa

In our proposal for the requirements of an IAT sentinel site network, we suggested that sites in the network should be close to sites of alien tree propagules. Plantations of alien tree species are likely to act as a major source of new invasions (Richardson and Brown 1986; Richardson and Rejmánek 2011; Dodet and Collet 2012) and should therefore form a major part of any IAT sentinel site network. Of the alien species used in commercial plantations, the most commonly planted species are from the genera Eucalyptus 

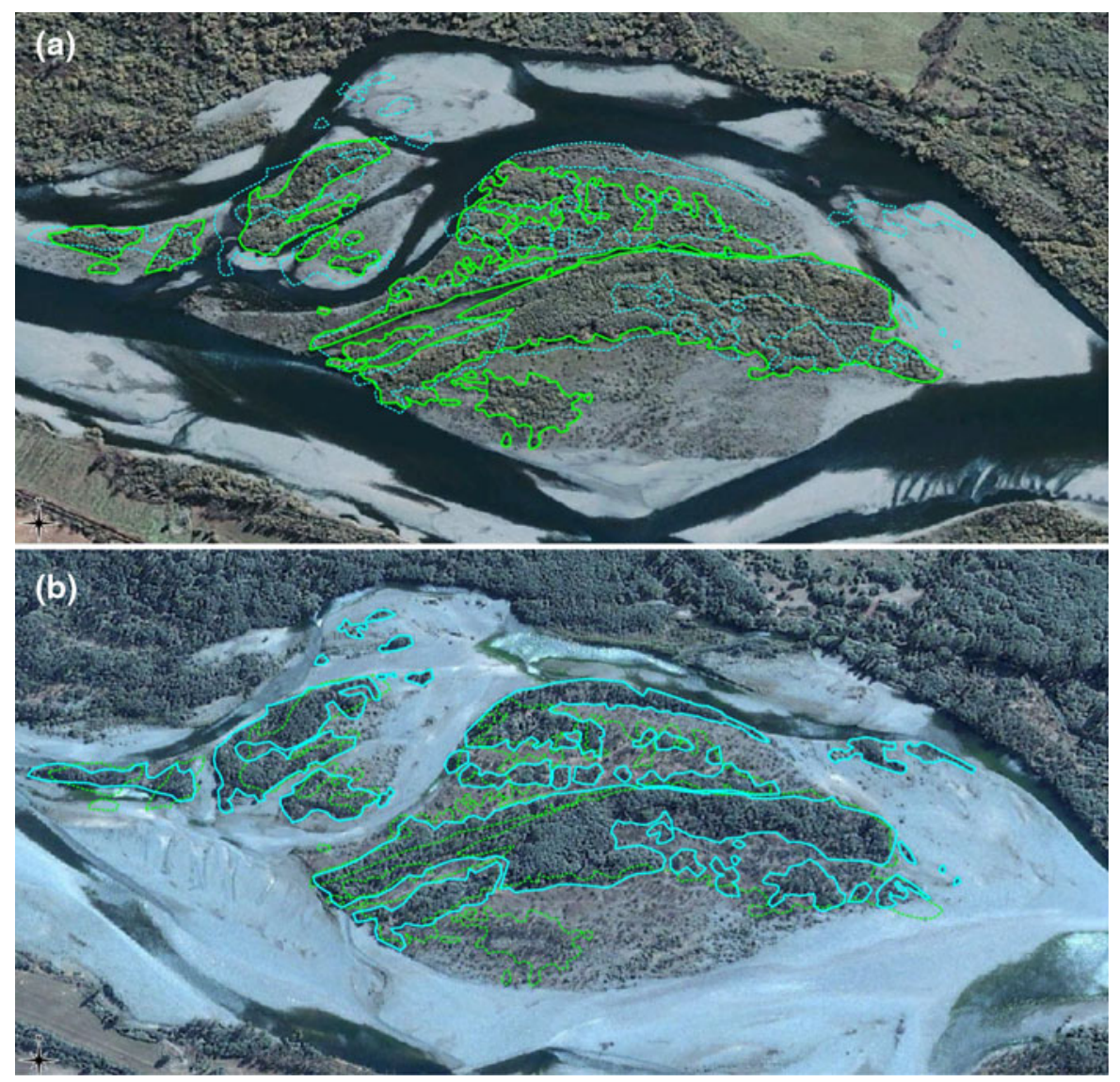

Fig. 3 Stands of Acacia dealbata along the Rio Nuble near the city of Chillán in central Chile as seen in georeferenced Google Earth imagery from 2003 (a) and 2010 (b). Green lines show our visual interpretation of the boundaries of $A$. dealbata stands in 2003 and blue lines the boundaries in 2010

substantial misclassification of smaller pine plantations (possibly because of the coarse resolution of the NLC2000, which is intended for uses with a minimum mapping unit of 25 ha; Fairbanks et al. 2000). We visually inspected the NLC2000 plantations in GE and removed those that were incorrectly classified. For the remaining plantations, we found that plantation boundaries according to the NLC2000 were largely incorrect and so we redrew the boundaries, using GE imagery as a guide to the limits of planted areas, often relying on historical imagery to identify recently felled plantation areas, which were included within the plantation boundaries. To limit the extent of our sentinel sites, we created a $200 \mathrm{~m}$ buffer area around our redrawn plantations and projected this onto GE as a KML file (Supplementary file 4). We then visually inspected all of these sites in GE, recording: (1) the year of the earliest and most recently available 
imagery in GE; (2) the presence of plantation species recruits beyond the plantation boundaries, but still within the $200 \mathrm{~m}$ buffer area, in the most recently available imagery; (3) a qualitative estimation of the area occupied by these recruits; (4) presence of recruits in the oldest GE imagery; (4) evidence of clearing activities in imagery of any date; (5) a qualitative assessment of the change in area occupied by plantation species recruits between the oldest and most recent imagery; (6) whether forestry activities were ongoing in the most recent imagery; (7) a qualitative assessment of the amount of invasible land nearby; (8) the names of the image providers (and satellites when we could ascertain this) for the earliest and most recent images; (9) the spatial resolution of these images; and (10) whether Google Street View or Panoramio images that help to identify the invading species were available.

Based on our redrawn boundaries we identified a total of 33 large plantations within the study region, seven of which were planted with eucalypts, 23 with pines, and three with a mixture of pines and eucalypts (Table 2; Supplementary file 4). We relied partially on the NLC2000 classification for identifying the species planted, but where we had doubts about this classification we attempted to identify the planted species based on GE imagery or using Google Street View (available for 28/33 sites) or georeferenced Panoramio photos (available for 19/33 sites). We had great difficulty in defining the plantation boundaries for many sites. This highlights a major issue in that there is no up-to-date national inventory of plantations for South Africa, making it difficult to provide objective assessments of whether managers are controlling invasions around their plantations. Nonetheless, we identified recruitment within the buffer area for 21 of the 33 plantations (Table 2; Supplementary file 4), however with most invasions being relatively small (14 sites), although two were identified as being of intermediate size and six as being extensive (Table 2; Supplementary file 4). We found no difference between eucalypt and pine plantations in this regard with approximately half of the sites of either species showing evidence of recruitment in the buffer zone (pine $=14 / 23$ sites; eucalypt $=4 / 7$ sites; mixed $=$ $3 / 3$ sites; Fisher's exact test, $P$ value $>0.05$; Table 2 ; Supplementary file 4) and pine sites exhibiting no significantly greater increases in the area occupied by recruits between the oldest and most recent GE imagery (Increase: pine $=9 / 19$, eucalypt $=1 / 7$; Fisher's exact test, $P$ value $>0.05$; Table 2; Supplementary file 4). In almost a quarter of the sites invasions were not detected in the earliest GE imagery available, but were present in the most recent imagery, although it is possible that IATs were not detected in the earlier imagery because of the lower spatial resolution of these images relative to the most recent images (Generally $2.62 \mathrm{~m}$ for the earliest images, but as low as $4 \mathrm{~m}$, compared to $1.65 \mathrm{~m}$ for the most recent images for all sites; Table 2). All except three of the pine sites appear to be on-going operations (Table 2; Supplementary file 4), suggesting continued monitoring will be necessary, although even the plantations in which planting has ceased, monitoring will need to continue due to the large seedbank that is probably present. A qualitative assessment of the area of neighbouring land suitable for invasion by plantation species revealed that all except two sites had large areas that were potentially invasible (Table 2; Supplementary file 4), highlighting the importance of continued monitoring of these sites. Very few of the identified invaded areas for each site appear to have had extensive clearing operations in the period between the earliest and most recently available GE imagery (lots of clearing $=3$; some $=8$; none $=10$; uncertain or no invasions present $=12$; Table 2 ; Supplementary file 4).

The results described above, however, have not been validated with field-based observations and so should be treated with some caution. As the results from the previous two case studies show, it is not always possible to accurately map or identify IATs from GE imagery, and we cannot always be certain of detecting IAT spread from plantations, particularly for young trees and when image spatial resolution is too low (spatial resolution also tends to be poorer for older images, as was the case for our sentinel sites; Table 2). Such a network would, therefore, require field validation of some of the results. However, these results highlight the diverse and useful information that could be generated by a sentinel site network. For example, we were able to remotely and cheaply monitor invasions over time, get a rough estimate of invaded area and potentially invisible area, and validate or determine the species planted and/or invading using Google Street View or Panoramio photos. We suggest that with public input to monitoring such sites it could be possible to monitor a much larger area, providing a 


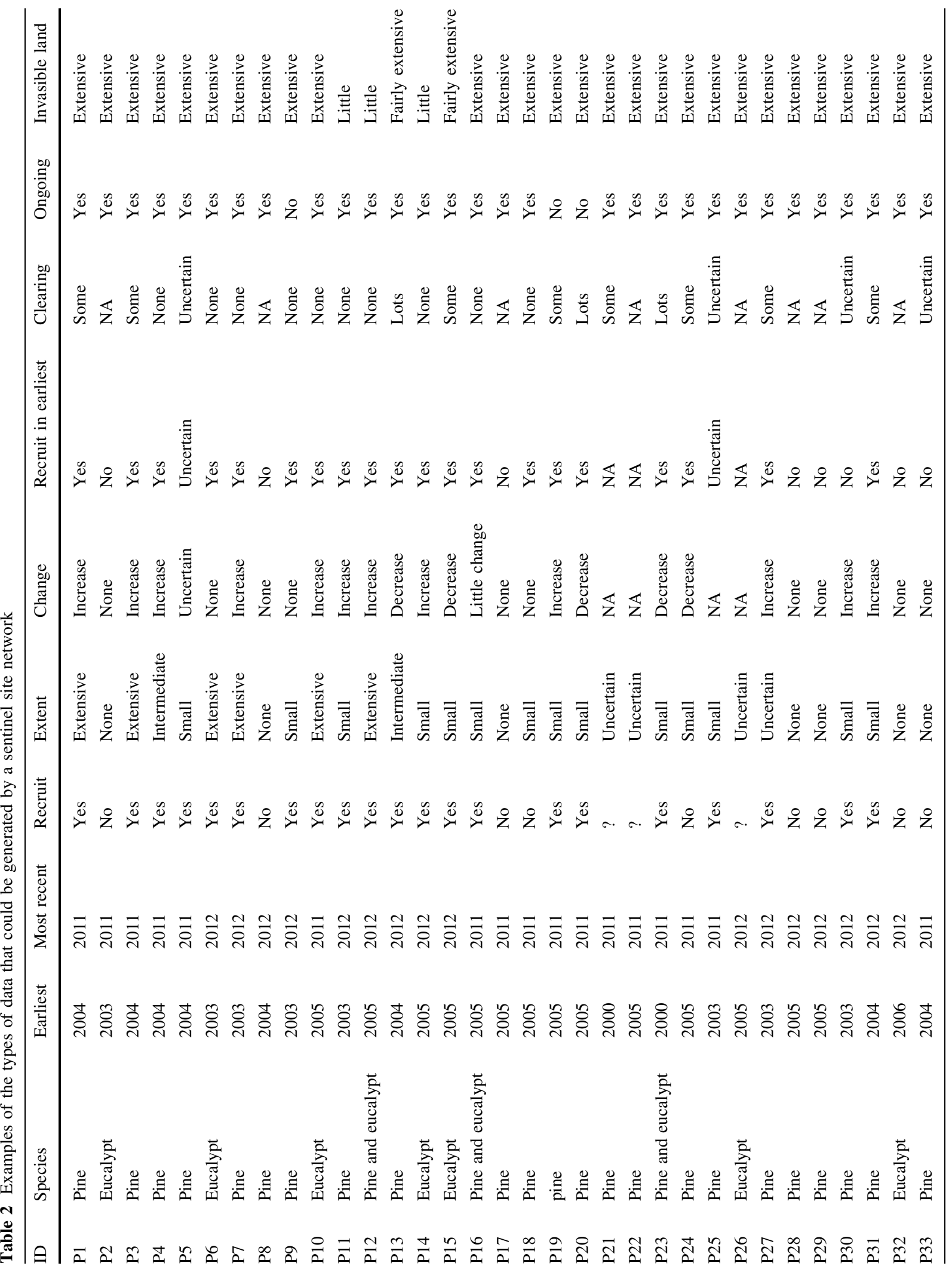




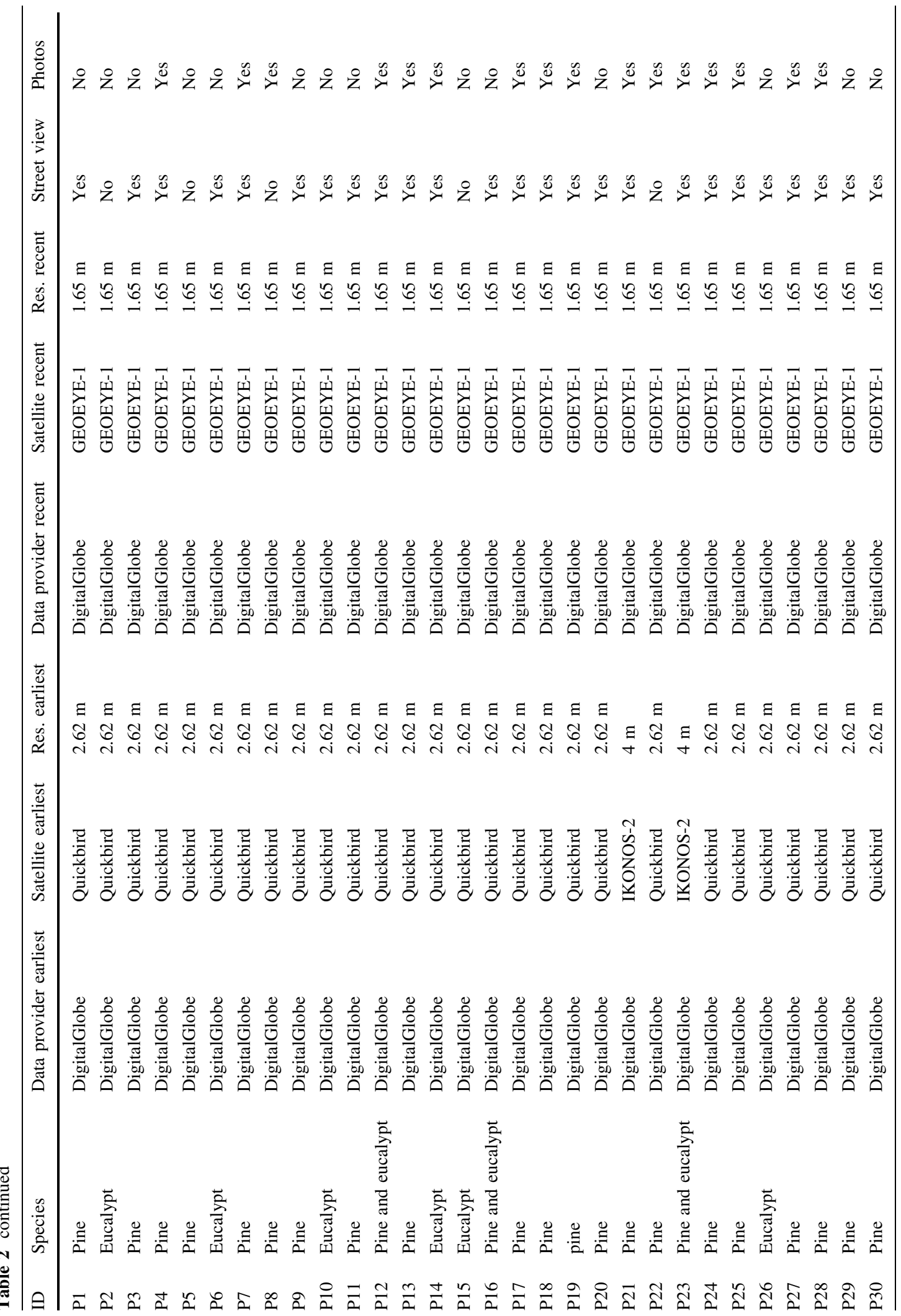




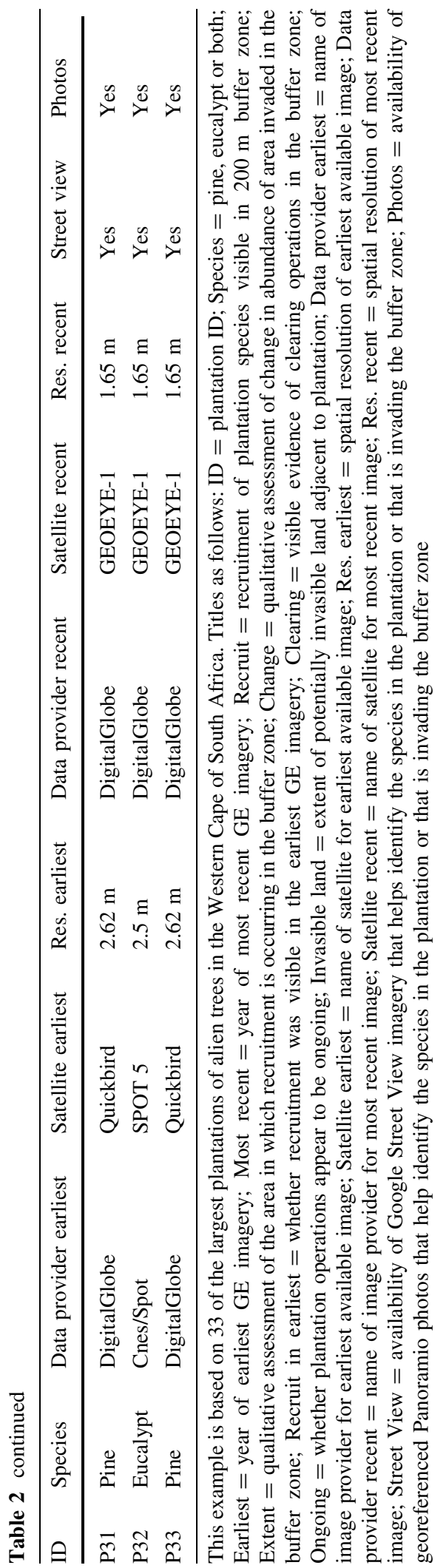

cheap method for organisations such as the Forestry Stewardship Council to ensure plantations of IATs are being effectively managed and also providing an early warning system for new invasions.

\section{Conclusions}

We have demonstrated how GE can be used for a number of invasion science applications including, generating information on the distributions, ecology and management of invasive alien trees, as well as providing a tool for early detection, monitoring, information sharing and awareness raising of these species. We also highlighted some of the problems with using GE in these ways, such as low resolution imagery, relatively few images for different time periods, incorrect georeferencing of images, and low spectral resolution of imagery from GE. This may lead one to question the utility and reliability of GE for the above-mentioned purposes. Depending on one's goals and budget it may be preferable to rely on other sources of aerial imagery, but for many researchers and managers, particularly in the developing world, GE (and other virtual globes) will be the only affordable option for obtaining high-resolution imagery. In addition, many of the current problems with GE imagery are likely to disappear or diminish in the future as the imagery and algorithms used to process them improve.

Observational approaches to ecology, such as we have demonstrated, have a long history dating back to the great naturalists such as Charles Darwin, and have the distinct advantage over experimental approaches in that research can be conducted across large spatial and temporal scales, and in situations that cannot be manipulated easily or ethically (Sagarin and Pauchard 2010). Recent advances in areas such as remote sensing and computing have greatly enhanced the capabilities of observational approaches (Sagarin and Pauchard 2010) and we suggest that GE, and other virtual globes, are an excellent case in point. While we have demonstrated the capabilities of GE for invasion science purposes, and for studying invasive alien trees in particular, the types of approaches we have proposed could have a wide range of applications for ecology in general. We demonstrated how one can acquire distribution, abundance and spatial 
information on IATs from GE, but any species or environmental feature that is easily identified in aerial imagery can be mapped and tracked over time. With its large number of users, GE provides an amazing tool for ecological education and awareness-raising, and there are already excellent examples that highlight human-induced, environmental changes, and the plight of endangered species, among others (http:// www.google.co.za/earth/outreach/index.html).

However, there are a number of impediments to a major uptake of GE, and other virtual globes, for scientific use. Metadata and the procedures used to format imagery are often unavailable, which severely limits the utility of GE imagery. This may be due to the fact that most imagery is "the property of governments and corporations", who restrict the terms of their use (Goodchild et al. 2012). As stated by Goodchild et al. (2012), there are strong arguments for increasing access to these types of data, not the least of which being that they can help to understand and alleviate major global issues, such as alien tree invasions. Some of this research will depend on citizen science, such as we suggested for sentinel site monitoring of IAT invasions, but there are also concerns over the quality and structure of data gathered in this way, and methods for addressing these concerns are likely to become increasingly important (Goodchild et al. 2012). Related to this, technology and methods for storing data derived from and generated for virtual globes will need to improve drastically in order to cope with the ever increasing amounts of data being generated (Goodchild et al. 2012). Another major impediment, particularly for scientists, is the lack of analytical tools in virtual globes, especially being able to link and extract information from disparate datasets (Goodchild et al. 2012). While free 2D-GIS software with extensive analytical capabilities, such as QGIS (Quantum GIS Development Team 2012), allow users access to some remote-sensed imagery, and virtual globes like ArcGIS Explorer have some analytical tools, the gap between 2D and 3D GIS is still large. Nevertheless, continued improvements to virtual globes should allow an ever greater number of scientific applications. Shortly after the launch of GE, Butler (2006) predicted that virtual globes such as Google Earth would change "the way we interact with spatial data" and it is our hope that this paper will aid this process by encouraging invasion scientists and managers to seize the opportunities in Google Earth for their work.
Acknowledgments We acknowledge financial support from the DST-NRF Centre of Excellence for Invasion Biology. Funding from the Oppenheimer Memorial Trust allowed VV and DMR to participate in the tree invasions workshop in Bariloche, Argentina, in September 2012 at which an early version of this paper was presented. We thank all delegates at the workshop for useful discussion and suggestions that have improved the paper. DMR acknowledges additional funding from the National Research Foundation (grant 85417) and the Hans Sigrist Foundation. Jocelyn Esquivel conducted the image photointerpretation for the Acacia dealbata aerial photography. AP funded by Fondecyt 1100792, ICM P05-002 and CONICYT PFB-23.

\section{References}

Ahern RG, Landis DA, Reznicek AA, Schemske DW (2010) Spread of exotic plants in the landscape: the role of time, growth habit, and history of invasiveness. Biol Invasions 12:3157-3169

Alston KP, Richardson DM (2006) The roles of habitat features, disturbance, and distance from putative source populations in structuring alien plant invasions at the urban/wildland interface on the Cape Peninsula, South Africa. Biol Cons 132:183-198

Asner GP, Huang C-Y (2011) Remote sensing. In: Simberloff D, Rejmánek M (eds) Encyclopedia of biological invasions, vol 3. University of California Press, Berkeley, pp 580-584

Aurambout JP, Pettit C (2008) Digital globes: gates to the digital Earth In: Ehlers M, Behncke K, Gerstengarbe F-W, Hillen F, Koppers L, Stroink L, Wächter J (eds) Digital earth summit on geoinformatics 2008: tools for global change research. Wichmann, Heidelberg, pp 233-238

Becker RH, Zmijewski KA, Crail T (2013) Seeing the forest for the invasives: mapping buckthorn in the Oak Openings. Biol Invasions 15:1-12

Begall S, Červený J, Neef J, Vojtěch O, Burda H (2008) Magnetic alignment in grazing and resting cattle and deer. Proc Natl Acad Sci USA 105:13451-13455

Benker CS, Langford RP, Pavlis TL (2011) Positional accuracy of the Google Earth terrain model derived from stratigraphic unconformities in the Big Bend region, Texas, USA. Geocarto Int 26:291-303

Biradar CM, Thenkabail PS, Noojipady P, Li Y, Dheeravath V, Turral H, Velpuri M, Gumma MK, Gangalakunta ORP, Cai XL, Xiao X, Schull MA, Alankara RD, Gunasinghe S, Mohideen S (2009) A global map of rainfed cropland areas (GMRCA) at the end of last millennium using remote sensing. Int J Appl Earth Obs 11:114-129

Boschetti M, Boschetti L, Oliveri S, Casati L, Canova I (2007) Tree species mapping with Airborne hyper-spectral MIVIS data: the Ticino Park study case. Int J Remote Sens 28:1251-1261

Bradley BA, Fleishman E (2008) Relationships between expanding pinyon-juniper cover and topography in the central Great Basin, Nevada. J Biogeogr 35:951-964

Breshears DD, Cobb NS, Rich PM, Price KP, Allen CD, Balice RG, Romme WH, Kastens JH, Floyd ML, Belnap J, 
Anderson JJ, Myers OB, Meyer CW (2005) Regional vegetation die-off in response to global-change-type drought. Proc Natl Acad Sci USA 102:15144-15148

Butler D (2006) Virtual globes: the web-wide world. Nature 439:776-778

Castro-Díez P, Godoy O, Saldaña A, Richardson DM (2011) Predicting invasiveness of Australian Acacia species on the basis of their native climatic affinities, life-history traits and human use. Divers Distrib 17:934-945

Catford JA, Vesk PA, Richardson DM, Pyšek P (2012) Quantifying levels of biological invasion: towards the objective classification of invaded and invasible ecosystems. Global Change Biol 18:44-62

Chytrý M, Pyšek P, Wild J, Pino J, Maskell LC, Vilà M (2009) European map of alien plant invasions based on the quantitative assessment across habitats. Divers Distrib 15:98-107

Conroy GC, Anemone RL, Van Regenmorter J, Addison A (2008) Google Earth, GIS, and the Great Divide: a new and simple method for sharing paleontological data. J Hum Evol 55:751-755

Development Core Team R (2013) R: a language and environment for statistical computing. R Foundation for Statistical Computing, Vienna

Dodet M, Collet C (2012) When should exotic forest plantation tree species be considered as an invasive threat and how should we treat them? Biol Invasions 14:1765-1778

ESRI (2009) ArcGIS. Environmental Systems Resource Institute, Redlands

Fairbanks DHK, Thompson MW, Vink DE, Newby TS, Van den Berg HM, Everard DA (2000) South African land-cover characteristics database: a synopsis of the landscape. S Afr J Sci 96:69-82

Forsyth GG, Richardson DM, Brown PJ, van Wilgen BW (2004) Rapid assessment of the invasive status of Eucalyptus species in two South African provinces. S Afr J Sci 100:77

Freedman DO, Kozarsky PE, Weld LH, Cetron MS (2008) GeoSentinel: the global emerging infections sentinel network of the International Society of Travel Medicine. J Travel Med 6:94-98

Fuller DO (2005) Remote detection of invasive Melaleuca trees (Melaleuca quinquenervia) in South Florida with multispectral IKONOS imagery. Int J Remote Sens 26:1057-1063

Gallagher RV, Leishman MR, Miller JT, Hui C, Richardson DM, Suda J, Trávníček P (2011) Invasiveness in introduced Australian acacias: the role of species traits and genome size. Divers Distrib 17:884-897

Goodchild MF, Guo H, Annoni A, Bian L, de Bie K, Campbell F, Craglia M, Ehlers M, van Genderen J, Jackson D, Lewis AJ, Pesaresi M, Remetey-Fülöpp G, Simpson R, Skidmore A, Wang C, Woodgate P (2012) Next-generation Digital Earth. Proc Natl Acad Sci USA 109:11088-11094

Google Earth Blog (2009) Improving Google Earth base imagery. http://www.gearthblog.com/blog/archives/2009/ 06/improving_google_earth_imagery.html. Accessed 6 June 2013

Google Earth User Guide (2013) Google Earth User Guide. http://support.google.com/earth/bin/answer.py?hl=en\&ans wer $=2445445$. Accessed 6 June 2013

Gundale MJ, Pauchard A, Langdon B, Peltzer DA, Maxwell BD, Nuñez MA (2014) Can model species be used to advance the field of invasion ecology? Biol Invasions (in press)
Higgins SI, Richardson DM, Cowling RM (2000) Using a dynamic landscape model for planning the management of alien plant invasions. Ecol Appl 10:1833-1848

Higgins SI, Richardson DM, Cowling RM (2001) Validation of a spatial simulation model of a spreading alien plant population. J Appl Ecol 38:571-584

Huang C-Y, Asner GP (2009) Applications of remote sensing to alien invasive plant studies. Sensors 9:4869-4889

Huang C-Y, Asner GP, Martin RE, Barger NN, Neff JC (2009) Multiscale analysis of tree cover and aboveground carbon stocks in pinyon-juniper woodlands. Ecol Appl 19:668-681

Huang D, Zhang R, Kim KC, Suarez AV (2012) Spatial pattern and determinants of the first detection locations of invasive alien species in mainland China. PLoS One 7:e31734

Hughes BJ, Martin GR, Reynolds SJ (2011) The use of Google EarthTM satellite imagery to detect the nests of masked boobies Sula dactylatra. Wildlife Biol 17:210-216

Hulme PE (2006) Beyond control: wider implications for the management of biological invasions. J Appl Ecol 43:835-847

Hulme PE (2011) Addressing the threat to biodiversity from botanic gardens. Trends Ecol Evol 26:168-174

Jennings SB, Brown ND, Sheil D (1999) Assessing forest canopies and understorey illumination: canopy closure, canopy cover and other measures. Forestry 72:59-74

Joseph G (2005) Data Analysis. In: Joseph G (ed) Fundamentals of remote sensing, 2nd edn. Universities Press, India, pp 319-348

Kotzé I, Beukes H, Van den Berg E, Newby T (2010) National invasive alien plant survey. Report Number: GW/A/2010/ 21, Agricultural Research Council, Pretoria

Kueffer C, McDougall K, Alexander J, Daehler C, Edwards P, Haider S, Milbau A, Parks C, Pauchard A, Reshi ZA, Rew LJ, Schroder M, Seipel T (2013) Plant invasions into mountain protected areas: assessment, prevention and control at multiple spatial scales. In: Foxcroft LC, Richardson DM, Pyšek P, Genovesi P (eds) Plant invasions in protected areas: patterns, problems and challenges. Invading Nature Series. Springer, Berlin (in press)

Langdon B, Pauchard A, Aguayo M (2010) Pinus contorta invasion in the Chilean Patagonia: local patterns in a global context. Biol Invasions 12:3961-3971

Lass LW, Prather TS, Glenn NF, Weber KT, Mundt JT, Pettingill $\mathrm{J}$ (2005) A review of remote sensing of invasive weeds and example of the early detection of spotted knapweed (Centaurea maculosa) and babysbreath (Gypsophila paniculata) with a hyperspectral sensor. Weed Sci 53:242-251

Le Maitre DC, van Wilgen BW, Gelderblom CM, Bailey C, Chapman RA, Nel JA (2002) Invasive alien trees and water resources in South Africa: case studies of the costs and benefits of management. Forest Ecol Manag 160:143-159

Levine JM, D'Antonio CM (2003) Forecasting biological invasions with increasing international trade. Conserv Biol 17:322-326

Maxwell BD, Lehnhoff E, Rew LJ (2009) The rationale for monitoring invasive plant populations as a crucial step for management. Invasive Plant Sci Manag 2:1-9

Mehta SV, Haight RG, Homans FR, Polasky S, Venette RC (2007) Optimal detection and control strategies for invasive species management. Ecol Econ 61:237-245 
Meyerson LA, Mooney HA (2007) Invasive alien species in an era of globalization. Front Ecol Env 5:199-208

Mumby PJ, Green EP, Edwards AJ, Clark CD (1999) The costeffectiveness of remote sensing for tropical coastal resources assessment and management. J Environ Manage 55:157-166

Osunkoya OO, Perrett C, Fernando C, Clark C, Raghu S (2012) Stand dynamics and spatial patterns across varying sites in the invasive Lantana camara L. (Verbenaceae). Plant Ecol 213:883-897

Pauchard A, Maheu-Giroux M (2007) Case study 11.1: Acacia dealbata invasion across multiple scales: Conspicuous flowering species can help us study invasion pattern and processes (pp 166-167). In: Strand H, Höft R, Strittholt J, Miles L, Horning N, Fosnight E (eds) Sourcebook on remote sensing and biodiversity indicators. Technical Series no. 32. Secretariat of the Convention on Biological Diversity, Montreal, pp 161-177

Pauchard A, Kueffer C, McDougall K, Alexander J, MIREN Consortium (2009) Global networks: a reply to Khuroo et al. Front Ecol Environ 7:518

Perrings C, Dalmazzone S, Williamson M, Mooney HA, Mack RN, McNeely JA et al (2005) The economics of biological invasions. In: Mooney HA, Mack RN, McNeely JA, Neville LE, Schei PJ, Waage JK (eds) Invasive alien species: a new synthesis. Island Press, Washington, pp 16-35

Pimentel D, Lach L, Zuniga R, Morrison D (2000) Environmental and economic costs of nonindigenous species in the United States. Bioscience 50:53-65

Potere D (2008) Horizontal positional accuracy of Google Earth's high-resolution imagery archive. Sensors 8:7973-7981

Quantum GIS Development Team (2012). Quantum GIS Geographic Information System. Open Source Geospatial Foundation Project. http://qgis.osgeo.org

Rejmánek M, Pitcairn MJ (2002) When is eradication of exotic pest plants a realistic goal? In: Veitch CR, Clout MN (eds) Turning the tide: the eradication of invasive species. Occasional papers of the IUCN Species Survival Commission. Issue 27 of IUCN occasional paper, pp 249-253

Richardson DM (1998) Forestry trees as invasive aliens. Conserv Biol 12:18-26

Richardson DM, Brown PJ (1986) Invasion of mesic mountain fynbos by Pinus radiata. S Afr J Bot 52:529-536

Richardson DM, Rejmánek M (2004) Conifers as invasive aliens: a global survey and predictive framework. Divers Distrib 10:321-331

Richardson DM, Rejmánek M (2011) Trees and shrubs as invasive alien species-a global review. Divers Distrib 17:788-809

Richardson DM, Thuiller W (2007) Home away from homeobjective mapping of high-risk source areas for plant introductions. Divers Distrib 13:299-312

Richardson DM, van Wilgen BW (2004) Invasive alien plants in South Africa: how well do we understand the ecological impacts? S Afr J Sci 100:45-52

Richardson DM, Rouget M, Rejmánek M (2004) Using natural experiments in the study of alien tree invasions: Opportunities and limitations. In: Gordon MS, Bartol SM (eds) Experimental approaches to conservation biology. University of California Press, Berkeley, pp 180-201
Richardson DM, van Wilgen BW, Nunez M (2008) Alien conifer invasions in South America-short fuse burning? Biol Invasions 10:573-577

Richardson DM, Carruthers J, Hui C, Impson FA, Miller JT, Robertson MP, Rouget M, Le Roux JJ, Wilson JR (2011) Human-mediated introductions of Australian acacias-a global experiment in biogeography. Divers Distrib 17:771-787

Robinson TP, van Klinken RD, Metternicht G (2008) Spatial and temporal rates and patterns of mesquite (Prosopis species) invasion in Western Australia. J Arid Environ 72:175-188

Rouget M, Richardson DM (2003) Inferring process from pattern in plant invasions: a semimechanistic model incorporating propagule pressure and environmental factors. Am Nat 162:713-724

Roura-Pascual N, Richardson DM, Krug R, Brown A, Chapman RA, Forsyth GG, Le Maitre DC, Robertson M, Stafford L, van Wilgen BW, Wannenburg A, Wessels N (2009) Ecology and management of alien plant invasions in South African fynbos: accommodating key complexities in objective decision making. Biol Conserv 142:1595-1604

Roura-Pascual N, Krug RM, Richardson DM, Hui C (2010) Spatially-explicit sensitivity analysis for conservation management: exploring the influence of decisions in invasive alien plant management. Divers Distrib 16:426-438

Rundel PW, Dickie IA, Richardson DM (2014) Tree invasions into treeless areas: Mechanisms and ecosystem processes. Biol Invasions. doi:10.1007/s10530-013-0614-9

Sagarin R, Pauchard A (2010) Observational approaches in ecology open new ground in a changing world. Front Ecol Environ 8:379-386

Sato HP, Harp EL (2009) Interpretation of earthquake-induced landslides triggered by the 12 May 2008, M7.9 Wenchuan earthquake in the Beichuan area, Sichuan Province, China using satellite imagery and Google Earth. Landslides 6:153-159

Sedjo RA (1999) The potential of high-yield plantation forestry for meeting timber needs. New For 17:339-359

Silvertown J (2009) A new dawn for citizen science. Trends Ecol Evol 24:467-471

Sserwanga A, Harris JC, Kigozi R, Menon M, Bukirwa H, Gasasira A, Kakeeto S, Kizito F, Quinto E, Rubahika D, Nasr S, Filler S, Kamya MR, Dorsey G (2011) Improved malaria case management through the implementation of a health facility-based sentinel site surveillance system in Uganda. PLoS ONE 6:e16316

Stensgaard AS, Saarnak CF, Utzinger J, Vounatsou P, Simoonga C, Mushinge G, Rahbek C, Møhlenberg F, Kristensen TK (2009) Virtual globes and geospatial health: the potential of new tools in the management and control of vector-borne diseases. Geospatial Health 3:127-141

Stow D, Hope A, Richardson D, Chen D, Garrison C, Service D (2000) Potential of colour-infrared digital camera imagery for inventory and mapping of alien plant invasions in South African shrublands. Int J Remote Sens 21:2965-2970

Taylor BT, Fernando P, Bauman AE, Williamson A, Craig JC, Redman S (2011) Measuring the quality of public open space using Google Earth. Am J Prev Med 40:105-112

Thuiller W, Richardson DM, Pyšek P, Midgley GF, Hughes GO, Rouget M (2005) Niche-based modelling as a tool for 
predicting the risk of alien plant invasions at a global scale. Glob Change Biol 11:2234-2250

Underwood E, Ustin S, Pauchard S, Maheu-Giroux M, Browne M (2007) Trends in invasive alien species. In: Strittholt J, Miles L, Horning N, Fosnight E (eds) Sourcebook on remote sensing and biodiversity indicators. Secretariat of the Convention on Biological Diversity, Montreal, Technical Series, no. 32, pp 160-177

van Wilgen BW, Richardson DM (2012) Three centuries of managing introduced conifers in South Africa: benefits, impacts, changing perceptions and conflict resolution. J Environ Manage 106:56-68

van Wilgen BW, Richardson DM, Le Maitre DC, Marais C, Magadlela D (2001) The economic consequences of alien plant invasions: examples of impacts and approaches to sustainable management in South Africa. Environ Dev Sustain 3:145-168

van Wilgen BW, Reyers B, Le Maitre DC, Richardson DM, Schonegevel L (2008) A biome-scale assessment of the impact of invasive alien plants on ecosystem services in South Africa. J Environ Manage 89:336-349 van Wilgen BW, Forsyth GG, Le Maitre DC, Wannenburgh A, Kotzé JD, van den Berg E, Henderson L (2012) An assessment of the effectiveness of a large, national-scale invasive alien plant control strategy in South Africa. Biol Conserv 148:28-38

Westbrooks R (2003) A National Early Detection and Rapid Response System for Invasive Plants in the United States: Conceptual Design. Federal Interagency Committee for the Management of Noxious and Exotic Weeds (FICMNEW)

Wilson JRU, Caplat P, Dickie IA Hui C, Maxwell BD, Nuñez MA, Pauchard A, Rejmánek M, Richardson DM, Robertson MP, Spear D, Webber BL, van Wilgen BW, Zenni RD (2014) A standardized set of metrics to assess and monitor tree invasions. Biol Invasions. doi:10.1007/s10530-013-0605-X

Yang K, Sun L-P, Huang Y-X, Yang G-J, Feng W, Hang D-R, Li W, Zhang J-F, Liang Y-S, Zhou X-N (2012) A real-time platform for monitoring schistosomiasis transmission supported by Google Earth and a web-based geographical information system. Geospatial Health 6:195-203

Yu L, Gong P (2012) Google Earth as a virtual globe tool for Earth science applications at the global scale: progress and perspectives. Int J Remote Sens 33:3966-3986 